TPAKTAT

ГЕОРГИЯ ГЕМИСТА ПЛИФОНА

"О ТОМ, ЧЕМ РАЗЛИЧАЮТСЯ

АРИСТОТЕЛЬ И ПЛАТОН»:

ИСТОРИЯ НАПИСАНИЯ

И ЗНАЧЕНИЕ

ДЛЯ ЗАПАДА И ВИЗАНТИИ

\author{
ТАТЬЯНА СЕНИНА \\ (МОНАХИНЯ КАССИЯ)
}

Кандидат философских наук, ведущий редактор Научно-образовательного чентра проблем философии, религии, культуры Санкт-Петербургского Государственного университета аэрокосмического приборостроения, ассочиированный научный сотрудник Сочиологического института РАН Федерального научно-исследовательского сочиологического чентра Российской Академии Наук.

Адрес: ул. Большая Морская, д. 67, лит. A, 190000, Санкт-Петербург, Россия.

E-mail:mon.kassia@gmail.com
Статья является введением

$\kappa$ публикации впервые

осуществленного перевода

на русский язык трактата

Георгия Гемиста Плифона

«О том, чем различаются

Аристотель и Платон».

Это сочинение было написано

Плибоном во время Ферраро-

Флорентийского собора

для его итальянских друзей-

гуманистов, которые очень

интересовались наследием Платона,

и стремились противопоставить

платонизм антихристианским

толкованиям на Аристотеля

в духе Аверроэса,

распространившимся в Европе

в XIV-XV вв. Плифон подверг

резкой критике взгляды Аристотеля

по многим пунктам, в том числе

о Боге-Творие, о душе, о добродетелях

и о случайном, противопоставляя

им учение Платона и подчеркивая

его преимущество, а также опроверг аристотелевскую критику теории идей. Этот трактат положил начало философской дискуссии между сторонниками Платона и Аристотеля, в ходе которой сначала произошел обмен полемическими трактатами между Плифоном и Георгием Схоларием, а затем появился ряд сочинений в защиту взглядов то Аристотеля, то Платона. Предпринятая Плифоном попьтка сравнительного философского и исторического комментария $\kappa$ трудам Платона и Аристотеля, вызвавшая широкую дискуссию, имела большое значение для дальнейшего изучения двух главных греческих мыслителей, а идеи Плифона и деятельность его учеников-платоников, прежде всего кардинала Виссариона и Иоанна Аргиропула, оказали несомненное влияние на итальянский Ренессанс. 
$\Gamma$ еоргий Гемист Плифон (ок. 1360-1452/541), византийский гуманист, последний философ Империи, полностью отошедший от христианства, разработав собственную религиозную систему на основе неоплатонизма, оставил несколько важных философских сочинений. К сожалению, самое главное из них, «Законы», после смерти философа было сожжено патриархом Геннадием Схоларием, который сохранил из него лишь часть в качестве доказательства, почему такое «нечестивое» произведение подлежало уничтожению. Этому варварскому акту предшествовала острая прижизненная полемика Схолария, тогда еще мирянина Георгия, с Плифоном. Дискуссия началась после того, как к Схоларию попал трактат философа «О том, чем различаются Аристотель и Платон» (издания: Lagarde 1973; Lagarde 1976; далее О различиях).

Это важное философское сочинение Плифон, по его собственному свидетельству в трактате «Против Схолариевой защиты Аристотеля», написал весной 1439 г. во Флоренции ${ }^{2}$ пока болел: «...мы в течение многих дней не выходили из дома, где поселились, и, разумеется, были удручены; так что оно было написано одновременно и для утешения нас самих в этой печали, и чтобы сделать нечто приятное приверженцам Платона» (Lagarde 1989, 438). Таким образом, по замечанию издательницы произведения Б. Лагард, перед нами, «скорее, не трактат с четко разработанным планом, а что-то вроде памятки, где Плифон зафиксировал для своих друзей основное из философских бесед, которые он с ними вел» (Lagarde 1973, 312).

О различиях положило начало жесткой дискуссии между Плифоном и Схоларием, который, будучи поклонником Аристотеля и к тому же томистом³, раскритиковал взгляды философа, написав в ответ огромный трактат «По поводу Плифоновых недоумений насчет Аристотеля» (Scholarios 1935), в несколько раз превышающий по объему трактат Гемиста. Плифон ответил на критику, написав «Против Схолариевой защиты Аристотеля» (издание: Lagarde 1989; далее - Против Схолария) - довольно пространное сочинение, в котором он более развернуто раскрывает идеи, в концентрированном виде изложенные в O различиях: речь идет о расхождениях между Платоном и Аристотелем в области логики, морали, физики и метафизики, особенно же о платоновском учении об идеях. Плифон доказывает преимущество Платона перед Аристотелем,

1 Обычно в качестве даты кончины Плифона указывают 1452 г., но есть вероятность, что в действительности он умер не за год до падения Константинополя, а годом позже (Hladký 2014, 2 и прим. 9). О нем и его мировоззрении см., прежде всего: Masai 1956; Медведев 1997; Woodhouse 1986; Tambrun 2006; Siniossoglou 2011; Hladký 2014.

2 Он был тогда в составе византийской делегации на Ферраро-Флорентийском соборе по поводу соединения Восточной и Западной церквей. В это время Плифону было уже около 80 лет - он родился между 1355 и 1360 гг. (Woodhouse 1986, 5).

3 Схоларий знал латынь и был восторженным почитателем Фомы Аквинского, сожалея лишь о том, что тот придерживался неправославного учения об исхождении Св. Духа (Жаворонков, Михайлов 2005, 613-614). 
подкрепляя свои рассуждения многочисленными пересказами и цитатами из обоих великих философов и их комментаторов ${ }^{4}$.

В О различиях Плифон сравнивает учение двух философов о Боге-Творце $\left(\S 5-13^{5}\right)$, о душе (§ 28-34), о добродетелях (§ 35-38) и о конечной цели (§ 3942), критикует мнения Аристотеля об омонимии сущего (§ 14-20), об общем и частном (§ 21-27), об эфире как «пятом теле» (§ 43-47), о целесообразности в природе и в искусстве (§ 48-52), о том, что есть вещи, совершающиеся без причины (§ 53-57), и о движении (§ 58-59). Везде Плифон подвергает Аристотеля жесткой критике и отдает предпочтение учению Платона.

Почти половину трактата ( $\$ 60$ и далее) занимает разбор критики Аристотелем платоновского учения об идеях. Плифон, близко следуя известному тексту 9-й главы I книги «Метафизики», разбирает возражения Стагирита и опровергает их, создавая, таким образом, комментарий на эту часть труда Аристотеля. Однако это не просто комментарий, но настоящий манифест платоника, соответствующий ожиданиям итальянских друзей и знакомых Гемиста, поклонников Платона.

Критика в адрес Аристотеля довольно резка: Гемист часто ироничен, говорит о «невежестве» Стагирита $(\S 2,21,57,59)$, обвиняет его в клевете $(\S 3,68$, 96), во введении новшеств (§ 45), в противоречии самому себе (§ 54, 57, 60). Тем не менее в конце своего разбора Плифон пишет, что сочинения Аристотеля стоит изучать «по причине содержащихся в них полезных вещей, однако надо знать, что к ним примешалось и много дурного» (§ 99). Относительно общей оценки толкования Аристотеля Плифоном здесь можно сослаться на мнение издателя трактата Б. Лагард, которая отмечает, что в целом «истолкование Плифоном учения Аристотеля нашло подтверждение у современных комментаторов» (Lagarde 1976, I, XXII).

Такие нападки на Аристотеля со стороны образованного византийца могут вызвать удивление: ведь в Византии Стагирит не только не подвергался критике, но изучался в рамках школьной программы и весьма почитался в качестве философа, если не считать, разумеется, его нехристианских взглядов. Богословы постоянно использовали разработанный Аристотелем категориальный аппарат. Такой столп православной Церкви как св. Григорий Палама в своем наиболее антифилософском сочинении «Триады в защиту священно-безмолвствующих», где подвергаются жесточайшей критике вся "внешняя» по отношению к христианству философия и светские науки, находит доброе слово только для Стагирита, говоря, что «философской премудрости лучше всех достигла душа Аристотеля» (Gr. Pal. Tr. II.1.7), Платона же, напротив, жестко критикует (Gr. Pal. Tr. II.1.20,22), а в «Ста пятидесяти главах» (гл. 4-5) ополчается на его

4 Отмечу, что лишь в нескольких случаях цитаты Плифона текстуально совпадают с оригинальными текстами.

5 Б. Лагард при публикации разделила текст Плифона на ненумерованные абзацы. Арабская нумерация параграфов в переводе сделана мной, для удобства отсылки. 
учение о Мировой Душе, прибегая за помощью к положениям все того же Аристотеля. Неудивительно, что сочинение Плифона вызвало в Византии у одних, в том числе учеников Гемиста и у самого императора, - недоуменные вопросы (Masai 1956, 337-338), а у других, прежде всего Георгия Схолария, - возмущение и стремление защитить Аристотеля.

Зато в Италии О различиях приняли очень хорошо, что опять же неудивительно: ведь Плифон писал свое сочинение именно для итальянской аудитории, ориентируясь на те проблемы, с которым пришлось столкнуться тамошним гуманистам. Что касается западных схоластов-аристотеликов, то они, ввиду незнания греческого, сочинения Плифона не читали, а потому и возражений от них не последовало. Плифон же обращался именно к гуманистам, «приверженцам Платона», к аудитории, уже готовой услышать от него критику в адрес Аристотеля. Всего через несколько месяцев после появления О различиях, Лоренцо Валла написал свои три книги Repastinatio dialecticae et philosophiae, направленные против Аристотеля и его последователей. Валла знал греческий и теоретически мог ознакомиться с сочинением Плифона, однако, судя по всему, писал самостоятельно (Woodhouse 1986, 228 и прим. 68); в любом случае «его сочинение свидетельствует не только о том, что гуманистические круги были готовы слушать критику Плифона, но и о том, что их влекло к ней их собственное желание» (Masai 1956, 338).

Рост интереса к платонизму в Италии XIV-XV вв. во многом вызван борьбой с аверроизмом, в котором видели опасность для христианства. В Европе после «темных веков» новое открытие Аристотеля происходило на основе переводов с арабского текстов философа и его комментаторов, из которых большой популярностью стали пользоваться толкования арабо-испанского аристотелика XII в. Ибн Рушда (Аверроэса). Аверроисты отстаивали философию, воплощенную для них в энциклопедической системе Аристотеля, и не заботились о ее согласовании с христианским вероучением, выдвинув концепцию «двойственной истины», обосновывавшую независимость истин разума от истин Откровения, философии от религии. Несмотря на то, что во Франции аверроизм был церковно осужден в 1270-х гг., он продолжал распространяться по Европе, в том числе в Италии (Ефремова 2010).

B XIV в. Франческо Петрарка написал целый полемический трактат против аристотеликов - De sui ipsius et multorum ignorantia, указывая, что схоластики изучают массу подробностей о жизни разных животных, но все эти вещи, пусть даже они истинны, совершенно не приводят человека к достижению счастья, и что лучше изучать не устройство животных, а природу человека. Петрарка настаивал на том, что современные ему аристотелики изобрели новую, нехристианскую религию, а над благочестивыми христианами, в том числе над ним самим, когда он пытается возражать им, насмехаются как над неучами. Согласно Петрарке, эти люди говорят, что ничто не рождается из ничего и не уходит в ничто, чем противоречат не только учению Платона о создании мира, но и самой Библии. Петрарка обвиняет в распространении этих заблуждений 
Аверроэса и заявляет, что Аристотель может быть идолом лишь для черни, тогда как избранные восхищаются Платоном. Сам Петрарка был знаком с учением Платона лишь опосредованно, через Цицерона и Августина, и, указывая, что аверроистский аристотелизм ведет к материализму и безбожию, призывал поскорее раздобыть оригинальные тексты Платона и найти греческих ученых, которые могли бы перевести их (Masai 1956, 348-352, со ссылками).

Таким образом, Петрарка показал путь своим последователям, и Плифон, прибыв в Италию, нашел там интеллектуалов уже не только весьма интересующихся Платоном, но и знающих греческий язык и способных воспринять комментарии к учению обоих знаменитых философов, неблагоприятные для Аристотеля. Хотя итальянские гуманисты далеко не всегда строго придерживались христианских догм, для платонизма XV в. в Италии в целом характерна полемика с аверроизмом, который, по мнению гуманистов, уничтожал религию и отрицал нематериальность и бессмертие души (Masai 1956, 353). В целом, однако, до XV в. Платон был плохо известен на Западе из-за отсутствия переводов (Woodhouse 1986, 133, 150, 216-217), поэтому итальянцы с большим интересом общались с Плифоном, который был известным знатоком и Платона, и Аристотеля. Несмотря на то, что Аристотель был на Западе известен куда лучше и даже в целом одобрялся Церковью (Woodhouse 1986, 151), итальянские ученые не были удовлетворены уровнем своего понимания его сочинений. В Против Схолария (Lagarde 1989, 372-374) Плифон упоминает о своих беседах по поводу толкований на Аристотеля с Пьетро Витали, настоятелем монастыря Гроттаферрата, о том, как Уго Бенци просил разъяснить одно место из сочинений Стагирита, и о том, что итальянцы, способные читать по-гречески, признавались Гемисту, что западные толкователи «намного уступают греческим толкователям в понимании мысли Аристотеля» (Lagarde 1989, 372-374). Плифон подарил им собственную книгу с сочинениями Платона, которая вскоре попала к Козимо Медичи, а потом к Марсилио Фичино (Tambrun 2006, 17). Несколько копий О различиях были розданы друзьям Плифона в Италии ${ }^{6}$, тогда как автограф, по-видимому, забрал себе ученик Плифона, знаменитый греческий гуманист Виссарион Никейский - рукопись сохранилась в его личном собрании в библиотеке Сан-Марко. Впоследствии сочинение активно переписывали, и в библиотеках сохранилось много его копий (Woodhouse 1986, 219).

Как заметил Ф. Мазэ, между византийскими и западными гуманистами существовало важное различие: «В то время как у греков источником для вольнодумства служил платонизм, на Западе свободомыслящие ученые происходили из аристотеликов. От этого источника западные вольнодумцы почерпнули ярко выраженную установку на естественные науки и материализм, тогда как в Византии они исповедовали возвышенный идеализм, законченным образцом которого является Плифон. Вследствие этого, в то время как

6 Об итальянских гуманистах, которые знали или могли знать Плифона, см.: Woodhouse 1986, 160-165. 
в Византии православные, такие как Георгий Схоларий, смело принимают аристотелизм (в его томистской форме), чтобы более эффективно бороться против платонизма, на Западе многие богословы все еще не решаются последовать за св. Фомой по пути уступок: их робкий интегризм влечет их к августинизму, то есть к христианскому платонизму» (Masai 1956, 353-354).

Общаясь с итальянскими гуманистами во Флоренции ${ }^{7}$, Плифон, по-видимому, быстро отметил эту особенность и не замедлил атаковать Аристотеля наиболее выгодным образом, выставив его перед западной аудиторией как философа, который, в отличие от Платона, своими рассуждениями наводит читателей на мысли о том, что душа человека не бессмертна (О различиях, § 32-34), и в конечном счете «скатывается к безбожию» (§ 51, ср.: § 10).

На родине Гемиста такое воззрение на Стагирита было непривычным, поэтому реакция на О различиях была довольно бурной (Woodhouse 1986, 228239). Однако, если Виссарион и император Иоанн VIII Палеолог попросили у Плифона разъяснений с чисто философской стороны, то Георгий Схоларий ополчился против его воззрений не только потому, что хотел защитить Аристотеля: он увидел в проплатонических рассуждениях философа из Мистры, и особенно в его детерминизме - учении о том, что все совершается не беспричинно и по необходимости (О различиях, § 53-57), угрозу для самого христианского вероучения, поскольку еще до этого слышал о существовании антихристианских «Законов» Плифона ${ }^{8}$. Философские споры на эту тему не стихли даже и после смерти Плифона, с падением Византии переместившись на Запад. В 1458 г. Георгий Трапезундский написал сочинение «Сравнение Аристотеля и Платона», в котором защищал Аристотеля, а Платона назвал источником всякой ереси и обличил Плифона за его платоническую религию (Tambrun 2006, 263). Посмертно критиковали Плифона и защищали Аристотеля также Матфей Камариот и Феодор Газа (Медведев 1997, 46-47; Siniossoglou 2011, 133).

В защиту учения Платона выступили ученики Плифона: Виссарион Никейский, Иоанн Аргиропул, Михаил Апостол, Димитрий Рауль Кавакис. Дом Виссариона в Риме, по выражению И. П. Медведева, «стал своеобразным эпицентром платонической экспансии, а его богатейшее собрание греческих рукописей, среди которых виднейшее место занимали сочинения Платона и платоников, - материальной основой этой экспансии и базой, на которой покоится вся рукописная традиция платонизма» (Медведев 1997, 90). Марсилио Фичино знал и широко использовал сочинения Плифона, хотя редко его упоминал, поскольку не пошел его путем - не решился расстаться с христианством, но приспособил философию Гемиста под свой проект «возрождения христианства» (Tambrun 2006, 241-247). Хотя жесткий детерминизм Плифона не могли принять в Италии, несмотря на весь интерес к платонизму, интеллектуалы

7 Судя по всему, итальянского и латыни Плифон не знал или, по крайней мере, не знал на уровне, необходимом для общения на сложные темы, поэтому у него наверняка был переводчик - возможно, эту роль сыграл Леонардо Бруни (Woodhouse 1986, 165).

8 Подробнее о реакции Схолария на О различиях см.: Woodhouse 1986, 240-266. 
итальянского Возрождения широко использовали плифоновские темы, хотя и в иных смысловых контекстах, нежели философ из Мистры (Masai 1956, 367-373; Tambrun 2006, 261). Отчетливо прослеживается влияние идей Плифона, в том числе через его учеников, особенно Иоанна Аргиропула, на возникновение флорентийской Платоновской академии под руководством Фичино и на итальянский Ренессанс в целом (Masai 1956, 339-343, 374-377).

О различиях и Против Схолария Плифона выделяются тем, что он отказался от присущего прежним толкователям стремления примирить Платона с Аристотелем под тем предлогом, что различия между ними несущественны, но, напротив, указывал на эти различия и пытался объяснить их рационально: историческими обстоятельствами, тщеславием автора и другими мотивами, идущими от жизненного опыта и психологии. Помимо этого, Плифон изменил традиции прочтения этих философов сквозь призму христианства - за такой подход Гемист особенно резко критикует Схолария во втором трактате, указывая, что тот хочет видеть в сочинениях Аристотеля такое мировоззрение, которого у него не было и в помине. Внимательно исследуя тексты, Плифон стремился объяснить позиции философов строго на основе их сочинений, не «вчитывая» в них то, что хотели бы там видеть позднейшие, особенно христианские, толкователи. Его попытка сравнительного философского и исторического комментария к трудам Платона и Аристотеля, вызвавшая широкую дискуссию, имела большое значение для дальнейшего изучения двух главных греческих мыслителей.

Ниже публикуется текст подготовленного Татьяной Сениной перевода первых 25 параграфов трактата «О том, чем различаются Аристотель и Платон». В комментариях к переводу приводятся фрагменты трактата «Против Схолариевой защиты Аристотеля» также в переводе автора вступительной статьи. Комментарии подготовлены Олегом Ноговициным и Татьяной Сениной

\section{СПИСОК ЛИТЕРАТУРЫ}

Hladký V. (2014) The Philosophy of Gemistos Plethon. Platonism in Late Byzantium, between Hellenism and Orthodoxy. Farnham: Ashgate.

Lagarde B. (1973) "Le "De Differentiis" de Pléthon d'après l'autographe de la Marcienne». Byzantion. Vol. 43. P. 312-343.

Lagarde B. (1976) Georges Gémiste Pléthon. "Des Différences entre Platon et Aristote». Édition, traduction et commentaire. Thèse de doctorat. T. I-II. Paris: Université de Paris IV - Sorbonne.

Lagarde B. (1989) «George Gémiste Pléthon: Contre les objections de Scholarios en faveur d’Aristote (Réplique)». Byzantion. Vol. 59. P. 354-507.

Masai F. (1956) Pléthon et le Platonism de Mistra. Paris: Les Belles Lettres (Les classiques de l'humanisme). 
Scholarios (1935) «Гع $\tau \varepsilon ́ \lambda \varepsilon(»$. Oeuvres complètes de Gennade Scholarios. Publ. par L. Petit, X. A. Sideridès, M. Jugie. T. IV. Paris: Maison da la bonne presse. P. 1-116.

Siniossoglou N. (2011) Radical Platonism in Byzantium: Illumination and Utopia in Gemistos Plethon. Cambridge: Cambridge University Press (Cambridge Classical Studies).

Tambrun B. (2006) Pléthon. Le retour de Platon. Paris: J. Vrin (Philologie et Mercure).

Woodhouse C. M. (1986) George Gemistos Plethon. The Last of the Hellenes. Oxford: Clarendon Press.

Григорий Палама (1995) Триады в защиту священно-безмолвствующих. Пер., послесл. и комм. В. Вениаминова. М.: Канон (История христианской мысли в памятниках).

Григорий Палама (2006) Сто пятьдесят глав. Вступ. ст., пер., примеч. А. И. Сидорова. Краснодар: Текст (Патристика: тексты и исследования).

Ефремова Н. В. (2010) «Аверроизм». Новая философская энциклопедия. Под ред. В. С. Стёпина и др. М.: Мысль. С. 40-41.

Жаворонков П. И., Михайлов П. Б. (2005) «Геннадий II Схоларий». Православная энциклопедия. Т. 10: Второзаконие - Георгий. М.: Церковно-научный центр «Православная энциклопедия». С. 612-616.

Медведев И. П. (1997) Византийский гуманизм XIV-XV вв. СПб.: Алетейя (Византийская Библиотека).

\title{
GEORGE GEMISTOS PLETHON'S TREATISE “DE DIFFERENTIIS PLATONIS ET ARISTOTELIS": ITS HISTORY OF COMPOSITION AND SIGNIFICANCE FOR THE OCCIDENT AND BYZANTIUM
}

\author{
Tatiana Senina (nun Kassia) \\ PhD in philosophy, research fellow at the Research and Education Center for Religion, Philosophy, \\ and Culture Studies at St. Petersburg State University of Aerospace Instrumentation, Associate Research Fellow \\ at the Sociological institute of the Federal Center of Theoretical and Applied Sociology \\ of the Russian Academy of Sciences.
}

Address: 67A Bolshaya Morskaia str., St. Petersburg 190000, Russia.

E-mail:mon.kassia@gmail.com

KEYWORDS: Plethon, Aristotle, Plato, Platonism, Byzantine philosophy, Byzantine humanism, Italian humanism, Averroism, the Renaissance.

The article constitutes an introduction to the first Russian translation of the treatise "On the difference between Plato and Aristotle" by George Gemistos Plethon. This work was written by Plethon during the Council of Florence for his Italian fellow humanists, who were highly interested in Plato's heritage and sought to oppose Platonism to Averroes-style antichristian interpretations of Aristotle which circulated in Europe in the XIV-XV centuries. Plethon put Aristotle's views to severe criticism in many respects, including his ideas of God the creator, of the soul, virtues and the contingent, while citing against them Plato's doctrine and showing its superiority; he also refuted Aristotle's critique of the theory of Ideas. This treatise gave rise to the philosophical debate between adherents of Plato and those of Aristotle: first an exchange of polemical treatises between George Plethon and George Scholarios, then a number of works in defense of the views of Aristotle or Plato. The endeavor of a comparative philosophical and historical 
commentary to Plato's and Aristotle's works undertaken by Plethon provoked a wide debate and had much significance for further study of the two crucial Greek thinkers, while Plethon's ideas and his Platonist disciples' activity, above all that of cardinal Bessarion and John Arguropoulos had an indisputable influence on the Italian Renaissance.

\section{REFERENCES}

Efremova N. V. (2010) "Averroizm" [Averroism]. Novaya filosofskaya entsiklopediya [New Encyclopaedia of Philosophy] (ed. V. S. Stepin et al.). Moscow: Mysl': 40-41. (in Russian).

Gregory Palamas (1995) Triady v zashchitu svyashchenno-bezmolvstvuyushchikh [Triads for the Defense of Those Who Practice Sacred Quietude] (tr., comment. V. Veniaminov). Moscow: Kanon (Istoriya khristianskoy mysli v pamyatnikakh [History of Christian thought in monuments]). (in Russian).

Gregory Palamas (2006) Sto pyat'desyat glav [The One Hundred and Fifty Chapters] (intr., tr., comment. A. I. Sidorov). Krasnodar: Tekst (Patristika: teksty i issledovaniya [Patristics: texts and studies]). (in Russian).

Hladký V. (2014) The Philosophy of Gemistos Plethon. Platonism in Late Byzantium, between Hellenism and Orthodoxy. Farnham: Ashgate.

Lagarde B. (1973) “Le 'De Differentiis' de Pléthon d'après l'autographe de la Marcienne”. Byzantion. Vol. 43: 312-343.

Lagarde B. (1976) Georges Gémiste Pléthon. "Des Différences entre Platon et Aristote". Édition, traduction et commentaire. Thèse de doctorat. T. I-II. Paris: Université de Paris IV Sorbonne.

Lagarde B. (1989) “George Gémiste Pléthon: Contre les objections de Scholarios en faveur d’Aristote (Réplique)". Byzantion. Vol. 59: 354-507.

Masai F. (1956) Pléthon et le Platonism de Mistra. Paris: Les Belles Lettres (Les classiques de I'humanisme).

Medvedev I. P. (1997) Vizantiyskiy gumanizm XIV-XV vV. [Byzantine Humanism of the $14^{\text {th }}$ $15^{\text {th }}$ centuries]. St. Petersburg: Aleteyya (Vizantiyskaya Biblioteka [Byzantine Library]). (in Russian).

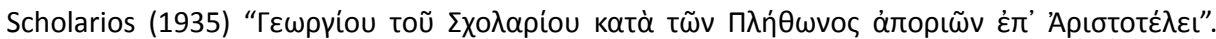
Oeuvres complètes de Gennade Scholarios (publ. par L. Petit, X. A. Sideridès, M. Jugie). T. IV. Paris: Maison da la bonne presse: 1-116.

Siniossoglou N. (2011) Radical Platonism in Byzantium: Illumination and Utopia in Gemistos Plethon. Cambridge: Cambridge University Press (Cambridge Classical Studies).

Tambrun B. (2006) Pléthon. Le retour de Platon. Paris: J. Vrin (Philologie et Mercure).

Woodhouse C. M. (1986) George Gemistos Plethon. The Last of the Hellenes. Oxford: Clarendon Press.

Zhavoronkov P. I., Mikhaylov P. B. (2005) "Gennadiy II Skholariy" [Gennadius II Scholarius]. Pravoslavnaya entsiklopediya [Orthodox Encyclopaedia]. T. 10. Moscow: Tserkovno-nauchnyy tsentr "Pravoslavnaya entsiklopediya": 612-616. (in Russian).

DOI: https://doi.org/10.31119/essephts.2019.4.1.11

ESSE: Studies in Philosophy and Theology. Vol. 4. No. 1. 2019. P. 350-358.

(c) Tatiana Senina (nun Kassia), 2019 